\title{
JOGO DE CENA: FERNANDO PESSOA E A GÊNESE DOS HETERÔNIMOS
}

\author{
Flávio Rodrigo Penteado ${ }^{1}$
}

RESUMO: O artigo propõe-se a discutir a essência ficcional da "Carta sobre a gênese dos heterônimos", como passou a ser conhecido o texto remetido em 13 jan. 1935 por Fernando Pessoa a Adolfo Casais Monteiro. Para tanto, situa-se a missiva no contexto da correspondência do autor e analisam-se questões referentes a processo de criação, memória e discurso epistolar, a fim de compreender a encenação do mito-Pessoa pelo escritor.

PALAVRAS-CHAVE: Fernando Pessoa; epistolografia; ficcionalidade; memória; processo de criação.

RÉSUMÉ: L'article propose discuter l'essence fictionnel de la «Lettre sur la genèse des hétéronymes», comme a été connu le texte remis par Fernando Pessoa à Adolfo Casais Monteiro le 13 janvier 1935. Pour cela, on situe la missive dans le contexte de la correspondance de l'auteur et on analyse des questions qui font référence au processus de création, à la mémoire et au discours epistolaire dans le but de comprendre la mise-em-scène du mythe-Pessoa par l'écrivain.

MOTS-CLÉS: Fernando Pessoa; epistolographie; ficcionalité; mémoire; processus de création.

1.

"Repudiei sempre que me compreendessem. Ser compreendido é prostituir-se" (PESSOA, 2009, p.149). Enunciada pelo narrador do Livro do desassossego, esta afirmação serve de contraponto a boa parte da atividade crítica desempenhada por Fernando Pessoa ao abordar sua própria produção. Bastante afeito à autoanálise, deixou dispersos inúmeros fragmentos em prosa dedicados a estabelecer parâmetros para a compreensão daquilo que realizou. Que esses textos não tenham sido conhecidos em vida é algo até certo ponto compreensível - embora alguns se destinassem a acompanhar potenciais publicações da obra heteronímica. Mais curioso, porém, é que escritos desse porte se façam presentes também em parcelas de sua correspondência. Neste sentido, merece destaque o texto endereçado em 13 jan. 1935 a Adolfo Casais Monteiro, comumente referido como "Carta sobre a gênese dos heterônimos".

\footnotetext{
1 Mestrando em Literatura Portuguesa pela Faculdade de Filosofia, Letras e Ciências Humanas da Universidade de São Paulo (FFLCH-USP). É bolsista da Fundação de Amparo à Pes quisa do Estado de São Paulo (FA PESP). Contato: flaviorodrigo.pc@hotmail.com.
} 
A primeira publicação da $\mathrm{Carta}^{2}$, acompanhada de um expressivo comentário de Casais Monteiro, deu-se em jun. 1937, no no 49 da revista Presença. Não obstante a notável argúcia do destinatário ao comentá-la, reconhecendo o que nela existe de "obra de arte" sem que se lhe negue o caráter de "documento informativo" (MONTEIRO, 1985, p.238), tamanha foi a dimensão adquirida pelo texto com o correr dos anos que, por vezes, não se dissociou a gênese heteronímica deste testemunho, como se fosse um acontecimento verídico e, logo, inquestionável.

Qualquer discussão a respeito da Carta, pois, convida a pensar o modo com que se relacionam - e, até certo ponto, se confundem - conceitos como realidade ou verdade, de um lado, e, de outro, fiç̧ão ou invenção. Embora pareçam noções óbvias, não existe consenso quanto à validade ou mesmo quanto à formulação de nenhuma delas. É fato, porém, que a ideia de realidade como sinônimo de verdade, tanto quanto a de fiç̧ão como correspondente de mentira, em tal medida está entranhada no senso comum que efetivamente se torna um desafio contornar abordagens que sejam, em algum grau, levianas do problema.

\section{2.}

Há certo mistério inerente à criação artística, mistério para o qual, durante muito tempo, buscou-se explicação em dois polos: inspiração ou técnica? Pulsão ou cálculo? Seja qual for a terminologia empregada, o pensamento ocidental continuamente oscilou entre esses extremos, da invocação à Musa ao pretenso cerebralismo absoluto. Deste modo, é possível destacar pelo menos dois "momentos decisivos" da discussão: de um lado, o culto ao gênio "titânico" desenvolvido no Sturm und Drang, movimento pré-romântico alemão; de outro, "A filosofia da composição", em que Edgar Allan Poe expõe a "matemática" da elaboração de "O Corvo".

A lembrança a estes dois momentos não é gratuita (especialmente do segundo, já que Pessoa traduziu o poema e, portanto, certamente travou contato com o texto que a ele se liga). Com efeito, já a estética da genialidade criadora postulada no Sturm und Drang era estritamente recurso para mascarar o esforço e o labor mobilizados na criação, de modo a permitir que a obra de arte surgisse como se fosse um produto puro da natureza, conforme Schiller reconheceria: "O produto estético pode e mesmo deve estar em correspondência

\footnotetext{
2 Para diferen ciar esta de outras cartas, emprega-se, neste artigo, a inicial maiúscula a fim de se referir à "Carta sobre a gênes e dos heterônimos".
} 
com as regras, mas deve parecer isento delas" (SCHILLER, 1793, apud GRÉSILLON, 2007, p.271).

Quanto "A filosofia da composição", nas palavras de Almuth Grésillon "uma ficção de gênese trazendo todas as marcas da invenção a posterior”" (GRÉSILLON, 2007, p.132), marcou época por constituir uma severa recusa à ideia de criação como fruto unívoco da inspiração - "sutil frenesi” ou "intuição estática", segundo Poe -, propondo uma visão da atividade literária atenta à "precisão e a sequência rígida de um problema matemático". Esta proposta deliberadamente passa ao largo das noções de acaso e imponderável, naturalmente envolvidos, em maior ou menor medida, no processo de criação: "Deixemos de parte, por ser sem importância para o poema per se, a circunstância, ou digamos, a necessidade que, em primeiro lugar, deu origem à intenção de compor um poema [...]” (POE, 2000, p.38).

Ao escamotear a motivação - aquilo que é fruto do impulso circunstancial -, Poe não deixa de apontar para a dupla natureza da ação criadora: não apenas inspiração, não apenas técnica; nem só pulsão, nem só cálculo, mas sim uma confluência de ambos: longe de se repelirem, é da tensão entre eles que advém a criação artística.

3.

Agora, pensemos um pouco a respeito do discurso epistolar. Em princípio, uma carta não existe para si, pressupondo um outro de quem se espera não apenas a leitura do que se escreveu como também uma resposta. Não é difícil, então, imaginá-la como elo de uma cadeia que envolve mais de um sujeito e, claro, outras cartas. Contudo, o fato de estar inserida em um conjunto não impede que seja lida de forma isolada:

Cada fragmento, isto é, cada carta funciona independentemente do conjunto - sendo delimitada, de sua natureza, por um cabeçalho, mais ou menos formalizado, e por uma assinatura final. À maneira de um poema de um livro de versos, ela existe por si e completa em si, como um todo significante, sem perder, por isso, o seu vínculo a um todo maior, sem deixar de representar um momento especial no continum da relação epistolar (SILVA, 2004, p.12).

É preciso não esquecer, ainda, que a carta, indispensável meio de comunicação por séculos, não se restringe à função comunicativa imediata ao integrar a correspondência de escritores, podendo ser concebida como espaço em que o remetente, por vezes, deposita a 
história de seu processo criativo e atua, assim, como leitor de si próprio. A este respeito, já se pronunciou o escritor alemão Hans Magnus Enzensberger:

Essa memória do processo, somente o autor pode possuir. Mas ele a possui realmente? Sua memória não é enganadora? Não está excluída a hipótese de o autor criar a gênese somente a posteriori e até mesmo, sem saber, de inventar uma gênese para determinado poema (ENZENSBERGER, 1962, apud GRÉSILLON, 2007, p.132).

A citação acima nos coloca diante de uma questão primordial: o problema da memória enquanto invenção, fictionis. De fato, durante o século XX não poucos escritores destacaram a precariedade intrínseca ao processo rememorativo, algo que o dramaturgo inglês Harold Pinter explorou em mais de uma peça - em Night (1969), por exemplo, um casal recorda a noite em que se conheceram; o detalhe é que as lembranças de um colidem com as do outro. Assim, o drama dessas personagens se fundamenta na impossibilidade de terem acesso à "verdade" dos acontecimentos senão através de uma representação mental destes, representação que é, por sua vez, recriada quando ganha concretude na fala. Em última instância, esse processo, bastante mediado, implica a dissolução desta "verdade" em si, na medida em que a duplica: não tendo nenhum dos dois o intuito de enganar o outro, passamos a considerar a "verdade" do homem e a "verdade" da mulher como "verdadeiras".

Lembramos a situação dessa peça de Pinter por acreditar que ela nos ajuda a perceber que o discurso da memória pode colidir com a realidade da escrita. Ademais, a carta, em tese, por ser documento privado, deveria apresentar uma perspectiva aparentemente mais "verdadeira", por encontrar-se livre dos olhos de uma plateia mais ampla. Particularmente na correspondência de um escritor, porém, os limites entre público e privado não possuem contornos tão definidos quanto se pode pensar: a quem efetivamente ele destina sua carta? Este questionamento, tão inócuo na aparência, destaca a indeterminação mobilizada na relação epistolar. Ora, na mesma medida em que convém não confundir o "eu" do poema com o "eu" do poeta, é preciso firmar alguma distinção entre quem escreve uma carta e quem de fato a remete; entre quem primeiro a recebe e quem de fato ocupa a posição de destinatário.

Assim, se enxergarmos a carta como lugar da memória (ato construtivo, como se viu), o suposto desnudamento da intimidade do escritor, por meio da sua correspondência, deve ser encarado com, pelo menos, alguma desconfiança. 
4.

De que maneira esses problemas se configuram na Carta? Um meio possível de se cercar a resposta é situá-la brevemente no contexto da correspondência do autor. Marcada por relativa diversidade de destinatários e assuntos abordados, a disposição cronológica das cartas que a forma, tal como propõe a edição mais recente, emparelha aquelas consideradas literárias e outras pouco significativas do ponto de vista estritamente artístico. Leve-se em conta, ainda, que o discurso epistolar é moldado pela presença do destinatário, favorecendo

a formulação de personae, pois o sujeito molda-se como personagem em face do interlocutor. Essa invenção de si (mise-en-scène), da qual o remetente pode ter maior ou menor grau de consciência, forja sempre estratégias de sedução (MORAES, 2007, p.74).

Nas cartas de Pessoa, também se verifica esta variação de registro, piegas e infantil, nas cartas endereçadas a Ofélia, por exemplo. Há, entretanto, casos em que ele mesmo assume determinada carta como parte de sua obra literá ria, como quando escreve uma carta a sua mãe e, depois de relê-la, resolve integrá-la ao Livro do desassossego:

A destinatária explícita avaliza uma carta familiar, íntima portanto, mas o conteúdo, no seu registo flutuante, introduz a literariedade e possibilita, pois, uma leitura segunda. Ao ser utilizada numa obra literária, pelo próprio expedidor, a carta perde não somente a sua privacidade, como se afirma, à leitura primeira, enquanto texto literário (sob forma epistolar). E a destinatária explícita - D. Maria Madalena Nogueira Pessoa "morre", transmuta-se na personagem mãe do sujeito do Livro do Desassossego e é como tal apenas recebida pelo leitor desprevenido (SILVA, 2004, p.25).

Percebe-se que, não raro, a carta prevê a leitura por terceiros. Tal característica é particularmente importante para a que este artigo focaliza, uma vez que, mais do que não se tratar de um texto qualquer (assim como aquela enviada à mãe, também a "Carta sobre a gênese dos heterônimos" transpira literariedade), não se trata de um destinatário qualquer. Desdobremos esta última afirmação.

À época da redação da Carta, Adolfo Casais Monteiro era não apenas um dos três jovens escritores à frente da Presença, que veiculava inúmeras colaborações de Pessoa, como também um interlocutor privilegiado deste. Ao manter permanente contato com os editores da publicação, ocasionalmente oferecendo a Casais e a Gaspar Simões 
substanciosas autoanálises, inclusive, parece inequívoco que o escritor se lhes dirige enquanto sujeitos individualizados e também como meios de acesso a um público mais amplo, ciente de que será lido por um grupo de críticos de elevada sensibilidade estética e que, através da ação destes, garantirá não apenas maior difusão de sua obra como também uma adequada recepção e interpretação desta.

De qualquer modo, por que ele teria respondido a Casais Monteiro, com inabitual presteza, a propósito de seu relato acerca da gênese dos heterônimos, tema que lhe era visivelmente caro? Tanto o era que, ao lhe questionar a respeito, o jovem crítico logo acrescenta: "Isto, bem o sinto, é talvez pedir demais" (MONTEIRO, 1985, p.255). Sem dúvida, o poeta poderia ter se esquivado da pergunta ou então demorado a retornar e, ao fazê-lo, por esquecimento, não respondesse - ambos os expedientes são relativamente comuns no conjunto epistolar pessoano, aliás. Bem ao contrário, Pessoa remeteu-lhe prontamente uma extensa resposta, apenas três dias depois. Como interpretar este gesto?

Uma possível motivação encontra-se nas páginas 18-19 do nº 35 da Presença (mar.mai. 1932), nas quais Adolfo Casais Monteiro manifesta sérias restrições a um prefácio assinado por Fernando Pessoa ao livro Acrônios, de Luís Pedro:

Neste prefácio, aquele que é o maior poeta português de hoje, mostra não ser admirável crítico de poesia; e por isso não resisto à tentação de tecer alguns comentários, na esperança, talvez, de que não seja verdade o que me pareceu ler, e que o poeta me ajude a melhor o compreender.

A relativamente longa ressalva de Casais Monteiro à conceituação por Pessoa, no texto referido, dos "três estádios na poesia, desde os gregos" não encontrou resistência no prefaciador. Acostumado a toda sorte de elogios por parte dos jovens intelectuais aglutinados em torno da Presença, é com alguma cortesia que acolhe estas palavras reprobatórias, conforme avisa a Gaspar Simões:

Gostei muito, aliás, de todo o número da Presença, incluindo os reparos do Adolfo Casais Monteiro ao meu prefácio a Acrónios. Talvez faça uma breve nota esclarecendo o que ele quer que eu esclareça. Neste momento ainda estou sob os reflexos da doença que tive, e, aliás, proibido pelo médico de trabalhar muito. Não que a Nota Explicativa exija muito espaço ou tempo; o que exige é disposição, e essa, por enquanto, faltame (PESSOA, 1999, p.268).

Na carta seguinte, volta a dar notícia da tal "Nota Explicativa": 
A propósito da Nota, a observação do Casais Monteiro é bem feita. O que houve, porém, da minha parte foi um lapso de redacção no passo do prefácio a que ele se refere. Como está, realmente, está mal [...] e estou deveras grato a Casais Monteiro por me dar a oportunidade de fazer esse esclarecimento, aperfeiçoando, ao mesmo tempo, uma passagem onde a redacção está muito imperfeita (PESSOA, 1999, p.269).

Fernando Pessoa não chegou, enfim, a redigi-la. Entretanto, mais de um ano depois, ao receber de Casais Monteiro (que até então jamais havia lhe escrito em particular) uma mensagem acompanhada de um livro de versos, assinala:

Como é esta a primeira carta que tenho ocasião de lhe escrever ${ }^{3}$ quero agradecer-lhe as palavras sempre amáveis que me tem dedicado em vária matéria publicada, que, sem ser por essas palavras, tenho sempre seguido com interesse e apreciado com admiração. Sobretudo the agradeço aquelas palavras em que, na crítica ao livro do Luís Pedro, discorda de mim, porque, à parte a natural vulnerabilidade de uma crítica prefacial amiga, me apanhou, de fato, num lapso de redação (PESSOA, 1999, p.314).

5.

Em vista do que foi exposto a respeito da relação entre Fernando Pessoa e Adolfo Casais Monteiro, é interessante notar a posição que o primeiro assume diante do segundo logo no início da Carta, começando por "pedir-lhe desculpa de lhe escrever neste papel de cópia" e, logo a seguir, completar que "mais vale, creio, o mau papel que o adiamento" (PESSOA, 1999, p.337). A postura aparentemente inferiorizada segue presente em todo este primeiro momento introdutório, em paralelo ao elogio das faculdades intelectuais do destinatário:

(...) conheço já suficientemente a sua independência mental, que, se me é permitido dizê-lo, muito aprovo e louvo. Nunca me propus ser Mestre ou Chefe - Mestre, porque não sei ensinar, nem sei se teria que ensinar; Chefe, porque nem sei estrelar ovos (PESSOA, 1999, p.337).

A essa digressão, em que Pessoa associa de modo espirituoso o sinônimo de Mestre, "Chefe", ao chef de cozinha - no caso, incapaz sequer de estrelar ovos -, segue-se outra, na qual expõe de forma mais explícita sua admiração pelo intelecto de Casais

\footnotetext{
3 Pessoa engana-se ao referir esta como a primeira carta ao jovem crítico e poeta, a qual efetivamente remeteu em 11 jan. 1930, agrad ecendo-lhe a oferta, desacompanhada de qualqu er mensagem anexa que não uma breve dedicatória na página de rosto, do livro de versos Confusão. Cf. PESSOA, 1999, p. 191-2.
} 
Monteiro. Trata-se do momento no qual afirma "absoluta concordância" em relação à opinião do crítico de que não foi feliz sua estreia literária "com um livro da natureza de Mensagem" (PESSOA, 1999, p.338). O curioso é que, ao expor as razões de publicação e, portanto, explicando a motivação do "erro", Pessoa não demora a concordar discordando de sua opinião: "Concordo consigo, disse, em que não foi feliz a estreia, que de mim mesmo fiz, com a publicação de Mensagem. Mas concordo com os factos que foi a melhor estreia que eu poderia fazer" (PESSOA, 1999, p.338).

No mesmo parágrafo, o poeta explica que privilegiar uma faceta não suficientemente manifestada em colaborações em revistas,

coincidiu, sem que eu o planeasse ou premeditasse (sou incapaz de premeditação prática), com um dos momentos críticos (no sentido original da palavra) de remodelação do subconsciente nacional. $O$ que fiz por acaso e se completou por conversa, fora exatamente talhado, com Esquadra e Compasso, pelo Grande Arquiteto (PESSOA, 1999, p.339).

Nesta passagem - antecedente a uma interrupção no fluxo testemunhal, a qual colocará fim ao instante introdutório da Carta -, Pessoa justapõe termos que chamam a atenção ora para a voluntariedade, ora para a não voluntariedade da criação: "coincidir" e "premeditar". Por certo, será essa a tônica do texto, do qual pululam termos como "aparecido", "tratei logo de descobrir", “instintiva”, "arranquei”, "ocorreu-me”, “ajustei”, "criei", "surgiu-me" etc. O depoimento, por conseguinte, é vincado por uma forte e constante tensão entre esses opostos.

Para além do que já se apontou, o trecho citado acima nos parece ser de especial interesse por dois motivos: em primeiro lugar, porque associa a ideia de "acaso" ao "Grande Arquiteto", quem "talhou” de maneira "exata", com "Esquadra e Compasso", as condições para o aparecimento de Mensagem; em segundo, porque essa última digressão prepara o próximo movimento do texto, iniciado no parágrafo seguinte:

(Interrompo. Não estou doido nem bêbado. Estou, porém, escrevendo diretamente, tão depressa quanto a máquina mo permite, e vou me servindo das expressões que me ocorrem, sem olhar a que literatura haja nelas. Suponha - e fará bem em supor, porque é verdade - que estou simplesmente falando consigo.) (PESSOA, 1999, p.339).

Aqui, Pessoa não apenas reclama plena sinceridade a seu testemunho, recuperando a (supostamente) desenfreada prática da escrita - o que não o "permite olhar a que 
literatura haja nela" - como também quase que impõe condições de entendimento da Carta a seu interlocutor, ao pedir-lhe que a tome por conversa, simplesmente porque se trata da verdade. Assim, com aparente displicência e muito senso retórico, dispõe as "regras do jogo" e somente então passa à enumeração das questões de que deve dar conta, levantadas por Casais Monteiro em carta anterior.

Antes de prosseguir, procedamos à maneira de Pessoa e interponhamosparênteses à análise: o tópico da espontaneidade, assim como o da sinceridade, é recorrente tanto na correspondência quanto na poesia deste autor, sendo preciso ressaltar estarem presentes no Espólio inúmeras variantes de missivas que escreveu. No caso da Carta, não é diferente: conservou-se um rascunho a uma passagem do texto, no qual se verificam variantes substanciais; dentre elas, a transferência do "dia triunfal" de 13 mar. 1914 para o dia 8 do mesmo mês e ano". Pode parecer apenas um detalhe ou, quem sabe, um lapso do escritor, que, ao reler o texto, pôde corrigi-lo. Todavia, para quem reclama escrever diretamente, tão depressa quanto a máquina permite, isto não é pouco. Sublinhemos, por fim, que não se trata de "pegar Pessoa na mentira", como se diz coloquialmente, mas sim de acentuar os mecanismos de persuasão e, portanto, de construção ficcional com que ele nos enreda (a Casais Monteiro, seu interlocutor imediato; aos companheiros deste na Presença, aos quais, no final da Carta, Pessoa autoriza a leitura do texto; e, finalmente, ao leitor vindouro).

O primeiro tópico, referente ao plano futuro de publicação de suas obras, merece relevo por sugerir um Pessoa desejoso de receber o já então cobiçado Prêmio Nobel de Literatura, mas sem demonstrá-lo explicitamente. Discorrendo a respeito d'O Banqueiro Anarquista, revela intenção de traduzi-lo para o inglês e publicá-lo na Inglaterra, tão logo esteja concluído: "Tal qual deve ficar, tem probabilidades europeias. (Não tome esta frase no sentido de Prémio Nobel imanente.)" (PESSOA, 1999, p.339).

A menção a O Banqueiro Anarquista não é aleatória. A pergunta de Casais Monteiro, logo lembra Pessoa, referia-se primordialmente ao plano de publicação de suas próximas obras de poesia, não prosa - mais especificamente um "tal grande volume dos poemas pequenos do Fernando Pessoa ele-mesmo”. A respeito deste, esclarece intenção de publicálo em fins do ano corrente de 1935. Quanto aos heterônimos Alberto Caeiro, Ricardo Reis e Álvaro de Campos, ele declara:

\footnotetext{
${ }^{4}$ Conforme relata nesta Carta, Pessoa teria viven dado um "dia triunfal" em que teria escrito, de um só jato, os "trinta e tantos" poemas de O guardador de rebanhos, atribuídos a Alberto Caeiro; a "Chuva oblíqua", assinada por Fernando Pessoa "ele-mesmo"; e, finalmente, a "Ode triunfal", legada a Álvaro de Campos.
} 
Nada disso poderei fazer, no sentido de publicar, exceto quando (...) me for dado o Prémio Nobel (...) Pensar, meu querido Casais Monteiro, que todos estes têm que ser, na prática da publicação, preteridos pelo Fernando Pessoa, impuro e simples! (PESSOA, 1999, p.340).

Como se vê, a passagem acima revela uma contradição, habilmente forjada por Pessoa: a produção poética dos três grandes heterônimos só será posta a lume quando lhe for concedido o Nobel pelo conjunto da obra, então composta somente por Mensagem (1934) e O Banqueiro Anarquista, isto é: as obras de maior vulto apareceriam somente quando da premiação máxima a ditas obras menores de um escritor genial.

O relato acerca da gênese heteronímica, enfim, começa a se esboçar por vias psicanalíticas, uma vez que o remetente alega estar a origem mental dos heterônimos em sua "tendência orgânica e constante para a despersonalização e para a simulação" (PESSOA, 1999, p.340). Explicada a tal origem "orgânica”, passa à história direta de seus heterônimos. Conduzindo seu interlocutor à saudosa infância do poeta, Pessoa envolve-o em nova digressão, no sentido de não explicar afinal a origem dos três grandes heterônimos, senão de "um certo Chevalier de Pas dos meus seis anos" (PESSOA, 1999, p.341).

Uma nova interrupção do fluxo testemunhal, novamente entre parênteses, promete introduzir a aguardada gênese dos três grandes heterônimos:

(Em eu começando a falar - e escrever à máquina é para mim falar -, custa-me a encontrar o travão. Basta de maçada para si, Casais Monteiro! Vou entrar na gênese dos meus heterônimos literários, que é, afinal, o que $\mathrm{V}$. quer saber. Em todo o caso, o que vai dito acima dá-lhe a história da mãe que os deu à luz.) (PESSOA, 1999, p.342).

A insistência em pôr em destaque o escrever diretamente à máquina, de forma corrente, denuncia a profunda intencionalidade da Carta, que se quer dar a conhecer como isenta de quaisquer artifícios ${ }^{5}$. Assim, enquanto configuração da realidade, o relato que nela se faz não pode significar outra coisa senão uma reconfiguração desta mesma realidade. $\mathrm{O}$ que se nos apresenta, por isso, é a ficção desta realidade e não a própria - a bem dizer, inacessível ao próprio poeta, que dela só pode dispor no espaço mental (não isento, conforme procuramos indicar, de dimensão ficcional).

\footnotetext{
5 Ressalte-se, ainda, que a edição por José Blanco da transcrição da Carta por Casais Monteiro, anota as emendas manuscritas feitas por Pessoa ao datiloscrito, as quais foram ocultadas pelo destinatário na primeira publicação do texto. Cf. MONTEIRO, 1985, p. 228-37.
} 
Ademais, se pensarmos que fazer literatura é deliberadamente provocar determinados efeitos sobre o leitor, não terá sido outra coisa o que Pessoa trama no trecho há pouco citado: este "basta de maçada" anuncia ao leitor o clímax de um texto que, baseado em idas e vindas, norteou-se pelo crescer de expectativas que demoravam a se concretizar.

O relato da gênese, pois, é a própria encarnação do dilema da criação artística discutido no princípio deste artigo: tensão entre pulsão e cálculo, prescrição e desejo. Repleto de movimentos de "possessão" e "retomada de consciência", o relato de Pessoa não apenas descortina o nascimento dos heterônimos diante dos olhos de seu interlocutor, como também parece ter a intenção de simular, no presente da escrita, um novo estado de elaboração e pulsão, semelhante ao do "dia triunfal", quando, ao se encaminhar para a conclusão do relato, enuncia: "Se há porém qualquer ponto em que precisa de um esclarecimento mais lúcido - estou escrevendo depressa, e quando escrevo depressa não sou muito lúcido -, diga, que de bom grado lho darei” (PESSOA, 1999, p.344).

6.

Neste artigo, procuramos seguir a sugestão de Casais Monteiro no comentário que fez à primeira publicação da Carta, no sentido de percebê-la não enquanto documento acessório, mas como obra de arte per se, na medida em que, para além de nela se assinalarem inequívocos traços de literariedade, podem-se observar insinuações ficcionais no relato. Assim, seja porque a memória está sujeita à ficção ou porque Fernando Pessoa nele tenha deliberadamente erguido um monumento ficcional, parece-nos inegável que neste texto se desenha uma encenação do mito-Pessoa pelo escritor - o que, de forma alguma, deve ser confundido com uma "mentira", uma "falácia", mas antes como uma tentativa muito engenhosa de trazer à luz a ficção deste mundo que, para fazer uso de uma imagem de Calderón, não passa de um grande palco. 


\section{Bibliografia}

GRÉSILLON, Almuth. Elementos de crítica genética: ler os manuscritos modernos. Trad. Cristina C. V. Bick, Letícia Colbachini, Simone N. Reis, Vincent Leclerq; supervisão de Patrícia C. R. Reuillard. Porto Alegre: Ed. UFRGS, 2007.

MORAES, Marcos Antônio de. "Ligações perigosas". In: Criação em debate. Org. Claudia Amigo Pino. São Paulo: Humanitas, 2007.

MONTEIRO, Adolfo Casais. A poesia de Fernando Pessoa. 2ed. Org. José Blanco. Lisboa: Imprensa Nacional - Casa da Moeda, 1985.

PESSOA, Fernando. Correspondência: 1923-1935. Org. Manuela Parreira da Silva. Lisboa: Assírio \& Alvim, 1999.

. Livro do desassossego. Org. Richard Zenith. São Paulo: Cia. das Letras, 2009.

POE, Edgar Allan. "A filosofia da composição". In: "O Corvo” e suas traduções. Trad. Milton Amado; Org. Ivo Barroso. 2ed. Rio de Janeiro: Lacerda Ed., 2000.

SILVA, Manuela Parreira da. Realidade e ficção: para uma biografia epistolar de Fernando Pessoa. Lisboa: Assírio \& Alvim, 2004. 